Knie J. 2022 · 4:

https://doi.org/10.1007/s43205-021-00139-3

Angenommen: 15. Dezember 2021

Online publiziert: 14. Januar 2022

(c) The Author(s), under exclusive licence to Springer Medizin Verlag $\mathrm{GmbH}$, ein Teil von Springer Nature 2022

\section{Ossifikation im M. popliteus als indirektes Zeichen einer chronischen posterolateralen Instabilität}

Alexander Palatinus · Björn H. Drews

St. Vinzenz Klinik Pfronten im Allgäu GmbH, Pfronten, Deutschland
Ein 46-jähriger Patient stellte sich mit seit 4 Wochen zunehmenden Schmerzen auf der Knieinnenseite und hierdurch deutlicher Bewegungseinschränkung vor. Anamnestisch gab er an, vor ca. 20 Jahren einen Sturz beim Fahrradfahren direkt auf das Knie erlitten zu haben. Er konnte seither zwar weiterhin Sport treiben, jedoch immer mit einem Unsicherheitsgefühl. Bereits in der Nativ-Röntgenaufnahme (• Abb. 1) fiel markant eine längerstreckige Ossifikation auf Höhe der posterolateralen Gelenkecke auf. Diese Verknöcherung stellte einen ersten indirekten Hinweis auf eine alte Verletzung der posterolateralen Ecke dar. In der klinischen Untersuchung zeigte sich eine varische Beinachse mit Varus thrust beim Gehen, Druckschmerz über dem medialen Gelenkspalt, II. ${ }^{\circ}$ laterale Aufklappbarkeit ab $10^{\circ}$ Flexion, eine 2-fach positive hintere Schublade ohne festen Anschlag und eine positive posterolaterale Rotationsschublade. Das im Anschluss durchgeführte MRT zeigte das nahezu vollständige Fehlen des hinteren Kreuzbandes (HKB). Die Ossifikation zeigte sich im M. popliteus und der Fortleitung in die Popliteussehne.

\section{Fazit}

Da Verletzungen des HKB selten sind, werden sie häufiger übersehen. Durch die in den Röntgenaufnahmen deutlich dargestellte Ossifikation des Musculus popliteus fand sich in diesem Fall bereits nativradiologisch ein indirekter Hinweis auf eine posterolaterale Instabilität, die eine weiterführende Diagnostik und operative Therapie erforderte.
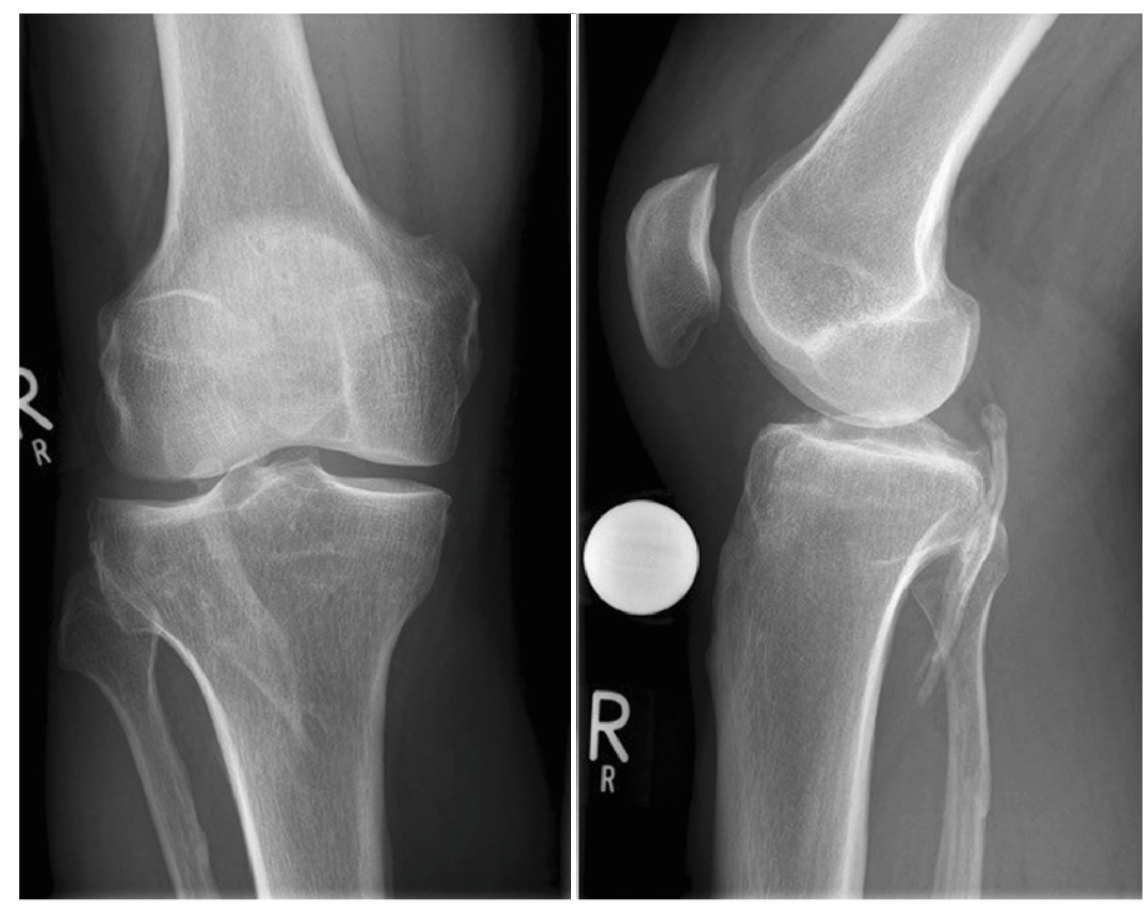

Abb. 1 A Deutlich sichtbare Ossifikation posterolateral und eine posteriore tibiale Translation im konventionellen Röntgen

\section{Korrespondenzadresse}

Dr. med. Björn H. Drews

St. Vinzenz Klinik Pfronten im Allgäu GmbH Kirchenweg 15, 87459 Pfronten, Deutschland bjoern.drews@vinzenz-klinik.de 